\title{
The next lap
}

T

o all my dear colleagues who have contributed to the Singapore Medical Journal (SMJ) as either a reader, author, reviewer or specialty editor, this is my note of thanks for the immense support you have given me over the last four years. Yes, it has indeed been four years since I stepped into the very 'big pair of shoes' that Prof Wilfred Peh passed on to me. I must thank him, once again, for all the guidance and for introducing me to many friends in the medical and scientific publication circle. They have been a great help to me and will undoubtedly remain firm friends beyond my involvement in the Journal.

Over the last four years, the goal was to move SMJ toward being the general medical journal of not just Singapore, but also the region. One of our key thrusts was to attract articles that are of high scientific value yet impactful to the daily practice of the clinician. This set in place multiple stresses to our manuscript review system. The gears in the system included the secretariat team, authors, specialty editors and reviewers. These gears were rapidly set in motion, but as with all systems, there have been occasional lapses and times when expectations have fallen short. For that, I offer my sincere apologies. However, I am encouraged that the team was able to considerably reduce the processing time for articles submitted to $S M$ J and this has been sustained for the last four years.

With the increasing quality of our articles, application for an ISI journal impact factor was made in 2009. It was indeed heartening when SMJ was awarded an initial impact factor of 0.73 in 2011. I am certain that with your continued contributions and support, the impact of the Journal will continue to increase. I believe this will consequently attract articles of higher quality, which will in turn enhance the experience of our readers. While the Editorial Board is cognizant of the value of the impact factor and will strive to increase the Journal's impact through the publishing of quality articles, we hope to do so without significantly changing its flavour. Our approach in providing medical information is a holistic one we hope our readers will enjoy and benefit as much from reading a research article with direct relevance to clinical practice as they would reading articles on medical education (PILL series and Pictorial Essay) or pioneers of medicine (Medicine in Stamps). Although some of these articles do not attract significant citations, they maintain SMJ's flavour and will remain a treasured part of the Journal.

This note will not be complete without the introduction of the next Editor-in-Chief - A/Prof Poh Kian Keong is currently a senior consultant at the National University Heart Centre, Singapore, and an Associate Professor at the Yong Loo Lin School of Medicine, National University of Singapore, Singapore. He has been a reviewer, specialty editor and deputy editor of SMJ for the last decade, and is also a regular contributor to the ECG series that many of our readers enjoy. Over the years, Kian Keong has contributed many ideas that have resulted in excellent outcomes for the Journal. As the old Chinese saying goes, 长江后浪推前浪 - and so the next generation will succeed and surpass the previous; I am confident that Kian Keong will bring SMJ to a much higher level. As all good things must come to an end, I now pass on the responsibility of charting the direction of $S M$ J into the capable hands of its next Editor-in-Chief. 